\title{
A STUDY OF THE IMMUNOGLOBULINS IN PREMATURE INFANTS
}

\author{
BY
}

\author{
J. C. HAWORTH, MARJORIE NORRIS, and LOUISE DILLING \\ From the Winnipeg Children's and General Hospitals and the \\ Department of Paediatrics, University of Manitoba, Canada
}

(RECEIVED FOR PUBLICATION SEPTEMBER 4, 1964)

The immunoglobulins are a family of proteins which may be identified in the plasma or serum by immunochemical methods. There are three main components (Franklin, 1962):

(1) $\gamma$-globulin $\left(\gamma_{2}\right)$ which has a sedimentation constant of $7 \mathrm{~S}$ and contains about $90 \%$ of the acquired antibodies. It has been shown that the concentration of $\gamma$-globulin in the plasma of newborn infants is equal to or higher than that of their mothers because of selective transfer across the placenta. After birth the concentration decreases to reach a low-level trough between 3 and 6 months of age, which may be about one-third of the initial level. This decrease is due to the combined effect of the normal rate of katabolism of the protein and the deficient synthesis of $\gamma$-globulin during the first weeks of life. The concentration then rises again to reach adult levels between the first and second year of life (Knapp and Routh, 1949; Orlandini, Sass-Kortsak, and Ebbs, 1955; Oberman, Gregory, Burke, Ross, and Rice, 1956).

(2) $\gamma_{1 \mathrm{~A}}$-globulin, which is also called $\beta_{2 \mathrm{~A}}$ because it migrates with the $\beta$-globulins on electrophoresis, also has a sedimentation constant of approximately $7 \mathrm{~S}$. It does not cross the placenta and has been shown by a number of workers to be absent from the plasma of newborn infants. Synthesis begins about the fourth week of life and the concentration rises slowly but probably does not reach adult levels until puberty (Hitzig, 1957, 1961 ; Scheidegger and Martin du Pan, 1957; West, Hong, and Holland, 1962). Not much is known about the antibody content of this fraction, but there is recent evidence that some of the skin sensitizing antibodies in allergic individuals may belong to the $\beta_{2 A}$-globulins (Heremans and Vaerman, 1962; Rockey and Kunkel, 1962) as well as Brucella abortus and diphtheria antibodies (Heremans, Vaerman, and Vaerman, 1963). Colostrum has been found to contain $\beta_{2 \mathrm{~A}}$ antibodies against a number of viruses and bacteria (Hodes, Berger, Ainbender, Hevizy, Zepp, and Kochwa, 1964).

(3) $\gamma_{1}$-macroglobulin or $\beta_{2 M}$ has a sedimentation constant of 19S. This fraction is also not capable of crossing the placenta but synthesis may occur at a slow rate in the foetus. After birth the rate of synthesis increases rapidly and it has been reported that adult levels may be reached at 9 months of age (Hitzig, 1957, 1961; Scheidegger and Martin du Pan, 1957; Franklin and Kunkel, 1958; West et al., 1962). $\beta_{2 \mathrm{M}}$-globulin contains Gram-negative agglutinins including typhoid $\mathrm{O}$ antibody as well as the rheumatoid factor. It has been shown that newborn infants inoculated with vaccines to Gram-negative organisms form antibodies as early as the seventh day of life which are 19S-macroglobulins. After a number of weeks the antibody is found to have changed to a 7S-globulin. In adults, initial antibody formation is also primarily of the 19S variety, but a change to $7 \mathrm{~S}$ occurs within a few days (Fink, Miller, Dorward, and LoSpalluto, 1962; LoSpalluto, Miller, Dorward, and Fink, 1962; Smith and Eitzman, 1964). Thus the 19S-macroglobulin fraction has been regarded as a more immature and perhaps even vestigial method of producing antibody. This recent work has also indicated that the newborn infant is by no means immunologically incompetent as was once thought, but is in fact perfectly well able to produce a humoral immune response by means of $19 \mathrm{~S}$ production.

We describe here a study that was made of the immunoglobulins in a group of 19 premature infants who were carefully observed from birth to 1 year of age, and some well into their second year of life. The intention was to record changes in the concentration of the three immunoglobulins in the plasma, and to find whether there was any correlation between these changes in concentration and episodes of naturally occurring infection and routine immunization procedures. 


\section{Material and Methods}

The subjects were 19 premature infants (11 males, 8 females) who were born at the Women's Pavilion of the Winnipeg General Hospital. Their birth weights ranged from 850 to $2,438 \mathrm{~g}$. and their estimated gestational ages ranged from 24 to 40 weeks. They were only selected in so far as they were born on the public service, that they were not private patients, and that it would be possible to follow them adequately in the premature baby clinic. They all received artificial milk feedings.

Blood was taken by heel prick as soon after birth as practicable and thereafter at approximately monthly intervals until the infants were 1 year of age. In a few instances it was possible to follow the babies into the second year of life, and blood was also obtained from some of the mothers. The blood was collected into heparinized capillary tubes and, after separation, the plasma was stored at $-20^{\circ} \mathrm{C}$. until the analyses could be performed. Our pooled adult standard serum was stored under similar conditions and the immunoglobulin content showed no deterioration. We have no reason to believe that any deterioration took place in the samples obtained from the subjects. In a few instances clotted blood was obtained and the serum analysed.

A qualitative analysis of each sample was undertaken by a modification of the micro-immunoelectrophoretic technique of Scheidegger (1955) and the slides were photographed for easier analysis and for permanent record. The three immunoglobulins, $\gamma_{2}, \beta_{2 A}$, and $\beta_{2 \mathrm{M}}$, were analysed quantitatively by the use of 'Immuno plates' (Hyland Laboratories, California, U.S.A.). These are clear plastic slides coated with agar gel which contains standardized specific antihuman $\gamma$-globulin, $\beta_{2 \mathrm{~A}}$-globulin, or $\beta_{2 \mathrm{~m}}$-globulin. Each slide contains 6 wells, into 3 of which were measured pooled control serum. For assay of the $\beta_{2 \mathrm{~A}^{-}}$and $\beta_{2 \mathrm{M}^{-}}$-globulins the control serum was used undiluted and diluted $1: 2$ and $1: 4$. For $\gamma_{2}$-globulin dilutions of $2: 5,1: 4$, and $1: 10$ were used. Into the other 3 wells different unknown plasma samples were measured. After incubation (4 hours at $37^{\circ} \mathrm{C}$. in the case of the $\gamma$-globulin 'Immuno plates' and 16 hours at room temperature in the case of the $\beta_{2 \mathrm{~A}}$ and $\beta_{2 \mathrm{M}}$ plates), the diameter of the zone of precipitate around each well was measured by means of a low power magnification viewer. Measurement was made by two observers and after practice it was found that the readings always agreed within $0 \cdot 1 \mathrm{~mm}$. Using semi-logarithmic paper the zone size of the pooled standard serum dilutions was plotted on the horizontal arithmetic scale and the globulin concentration on the vertical logarithmic scale. The concentration of the globulins in the unknown plasma samples could then be read from the graph. Samples containing globulins in concentrations too high to be plotted on the graph were diluted. Since only small amounts of each plasma sample were usually available it was necessary to perform the dilutions in the 'Immuno plate' wells, and this introduced some error. Fig. 1 shows typical examples of $\beta_{2 \Lambda^{-}}$and $\beta_{2 M^{-}}$globulin plates.

Each plasma or serum sample tested was compared with pooled adult serum collected from about 100 subjects. Through the courtesy of Dr. Kingdon Lou who recently supplied us with a reference serum with known globulin content established by means of purified antigens, we have been able to perform a quantitative assay of the immunoglobulins in our standard serum. The $\gamma_{2}$-globulin content was $1,100 \mathrm{mg} . / 100 \mathrm{ml}$., $\beta_{2 \mathrm{~A}}$ globulin $295 \mathrm{mg}$. $/ 100$ $\mathrm{ml}$., and $\beta_{2 \mathrm{M}}$-globulin $127 \mathrm{mg} . / 100 \mathrm{ml}$. These concentrations agree fairly well with those reported in the literature for normal adults (Fahey and Lawrence, 1963; Chodirker and Tomasi, 1963). We felt it advisable to express the concentration of the immunoglobulins obtained from the premature infants as a percentage of our normal adult serum rather than in $\mathrm{mg} . / 100 \mathrm{ml}$.

The reproducibility of the quantitation of the immunoglobulins by means of 'Immuno plates' was assessed. In 22 duplicate samples the standard deviation (SD) of the $\gamma$-globulin estimations was $\pm \mathbf{8 . 8 \%}$ of normal adult serum, for $\beta_{2 A}$ in 25 duplicate samples the SD was $\pm 4.7 \%$ of normal serum, and for $\beta_{2 \mathrm{M}}$ at concentrations of $100 \%$ or less of the adult serum the SD of 12 duplicate samples

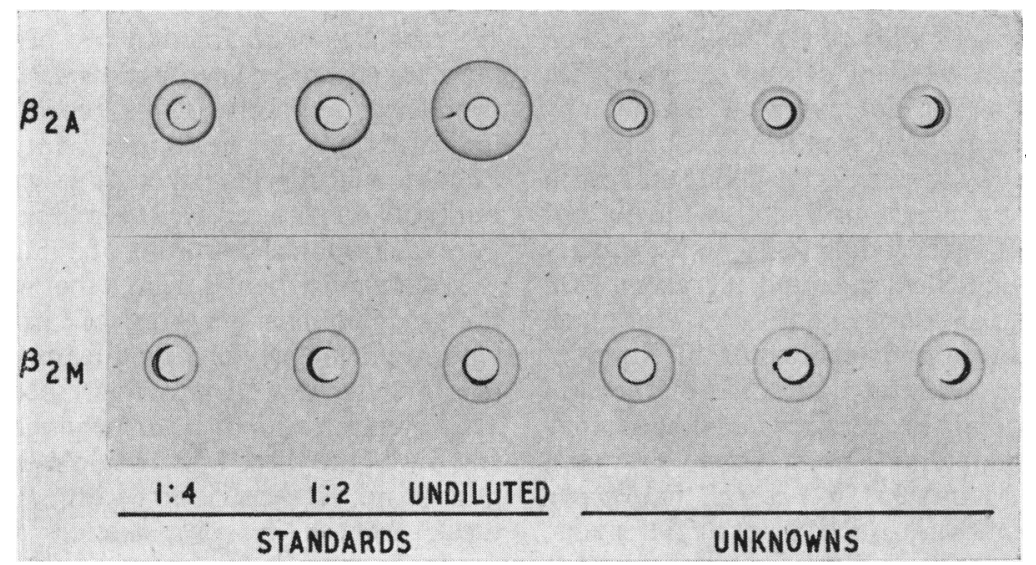

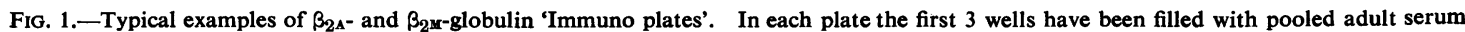
in dilutions of $1: 4,1: 2$, and undiluted, and the next 3 wells with 3 different unknown plasma samples. 
was $\pm 5.9 \%$. When the concentration of $\beta_{2 M}$ was greater than $100 \%$ of the normal serum, dilution of the unknown plasma or serum was necessary and the reproducibility was reduced. In 8 duplicate samples the SD was $\pm 28 \cdot 4 \%$ of adult normal serum.

A record was kept of all infections that occurred in infants and also of their immunizations.

\section{Results}

Fig. 2 is a scattergram of the concentrations of the $\gamma_{2}$-globulin in the infants in relation to their age. The range of values at any given age was very wide, but it may be seen that the mean concentration during the first four weeks was a little greater than the adult value. The mean level then decreased rapidly, as expected, to reach $25 \%$ of the adult value between 12 and 16 weeks. A slow rise then occurred to approximately $100 \%$ again at 1 year of age.

In Fig. 3 the concentrations of $\beta_{2 A^{-}}$-globulin have been plotted against age. At birth in most cases this fraction was not detectable (mean $2.8 \%$ of normal adult serum). A steady but slow rise then occurred in the mean level and at 1 year of age the level was $28 \%$. In only one infant was a level of $\beta_{2 \mathrm{~A}}$ greater than $100 \%$ recorded $(119 \%$ at 16 months in Case 8, see Fig. 7).

In Fig. 4 the $\beta_{2 M}$ concentrations are shown. Again there was a wide range of values. The levels at birth were low (mean $25 \%$ ) but thereafter a rapid increase occurred to reach a mean level of $100 \%$ at 20 to 24 weeks of age. Several very high levels were recorded after 20 weeks of age, 15 of $200 \%$ or greater and 3 greater than $300 \%$.

Figs. 5-9 illustrate the findings in 5 individual cases. Fig. 5 shows a graph of the immunoglobulin concentrations in Case 9, a male baby of 34 weeks' gestation, birth weight $2,058 \mathrm{~g}$. At 4 days of age he had absent $\beta_{2 A}$-globulin, $16 \% \beta_{2 M}$-globulin, and $64 \%$ $\gamma_{2}$-globulin. By 7 weeks the $\gamma$-globulin line of precipitation was very faint and the $\beta_{2 M}$ fraction had increased slightly on quantitative assay though no line could be seen on the immunoelectrophoretic slide. At 25 weeks the gamma globulin level was $56 \%$ and the $\beta_{2 M}$-globulin had reached $100 \%$. This baby had no infection and thrived normally until $\mathbf{4 0}$ weeks of age when he developed bronchitis and 4 weeks later pharyngitis. At this time (44 weeks of age) the $\beta_{2 M}$-globulin was $248 \%$, the $\gamma$-globulin $48 \%$, and the $\beta_{2 \mathrm{~A}}$-globulin $25.5 \%$. $\quad \beta_{2 \mathrm{~A}}$-globulin could not be identified by the qualitative technique in any sample.

Case 2 (a male, birth weight $1,134 \mathrm{~g}$., gestation 28 weeks) also had severe hypo- $\gamma$-globulinaemia at 12 to 16 weeks of age (Fig. 6). Unfortunately the sixth-day plasma sample was not suitable for quantitative $\gamma_{2}$-globulin estimation. This infant was

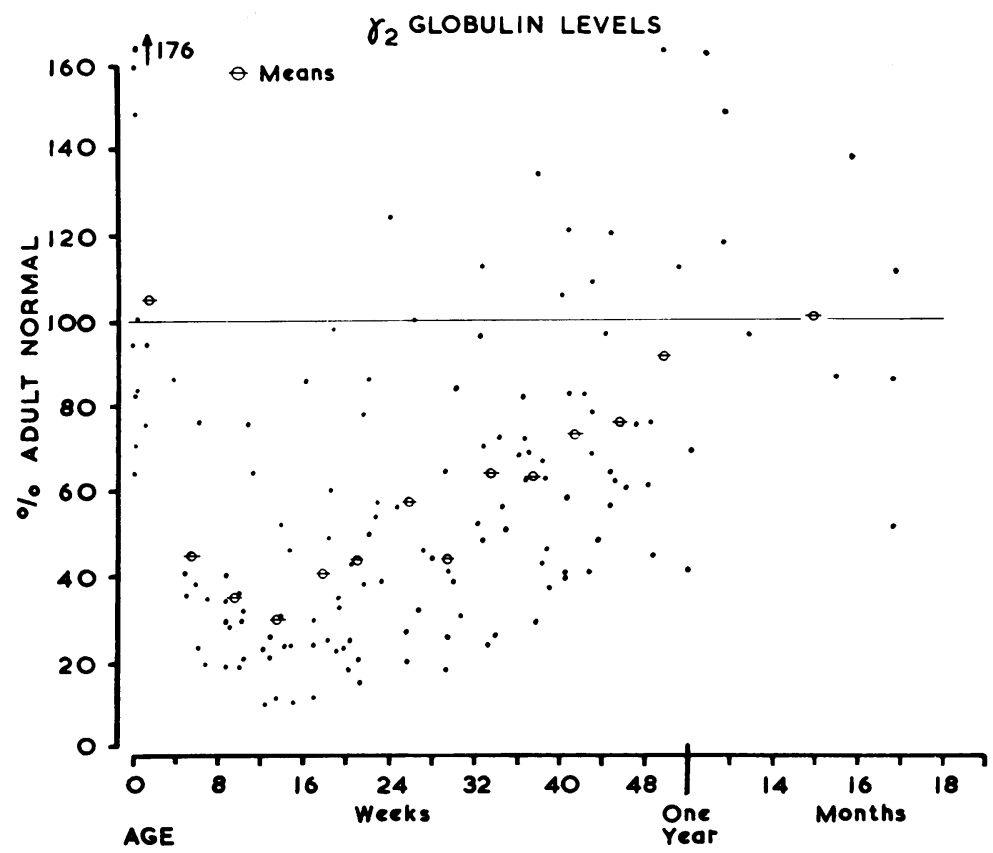

Fig. 2.-Scattergram of the $\gamma_{2}$-globulin levels in the 19 premature infants expressed as a percentage of the concentration in pooled normal adult serum and plotted against age of the infants. The mean levels $(\theta)$ have been calculated for each four-week period. Values obtained from infants over 1 year of age have been combined as a single mean value. 


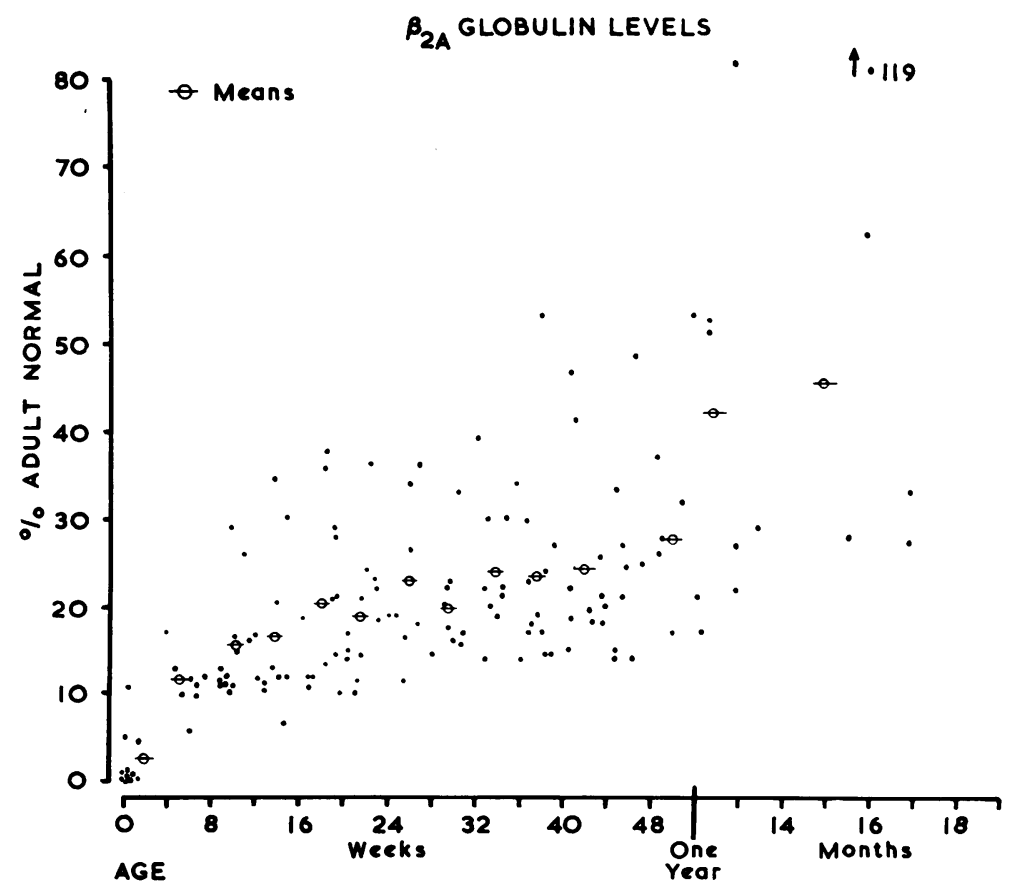

FIG. 3.-Scattergram of $\beta_{2 \Lambda}$-globulin levels. Legend otherwise as in Fig. 2.

ill with pneumonia at 7 weeks of age and again at 20 weeks of age. The immunoelectrophoretogram of the plasma at 12 weeks of age showed only a trace of $\gamma_{2}$-globulin $(10 \%)$ and the $\beta_{2 M}$-globulin concentra- tion was $62 \%$ of adult normal. By 29 weeks the $\gamma_{2}$-globulin fraction was clearly visible and the level had risen to $18 \%$. At 30 weeks he was exposed to measles and received $1 \mathrm{ml}$. of $\gamma$-globulin by intra-

$\beta_{2}$ MACROGLOBULIN LEVELS

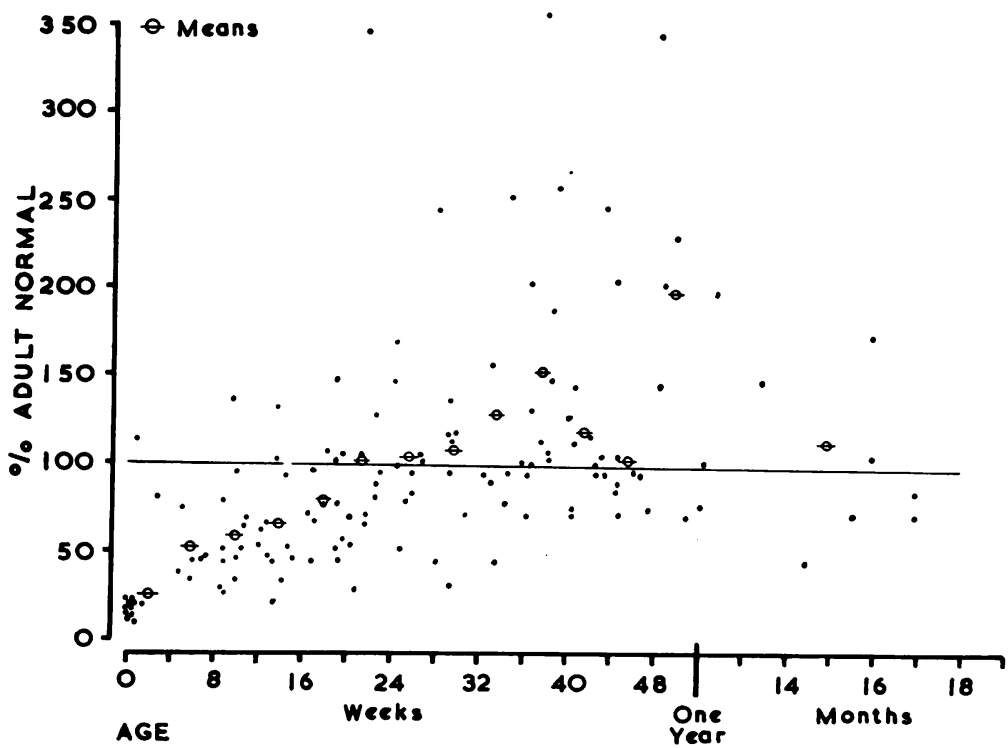

Fig. 4.-Scattergram of $B_{2}$-macroglobulin levels. Legend otherwise as in Fig. 2. 


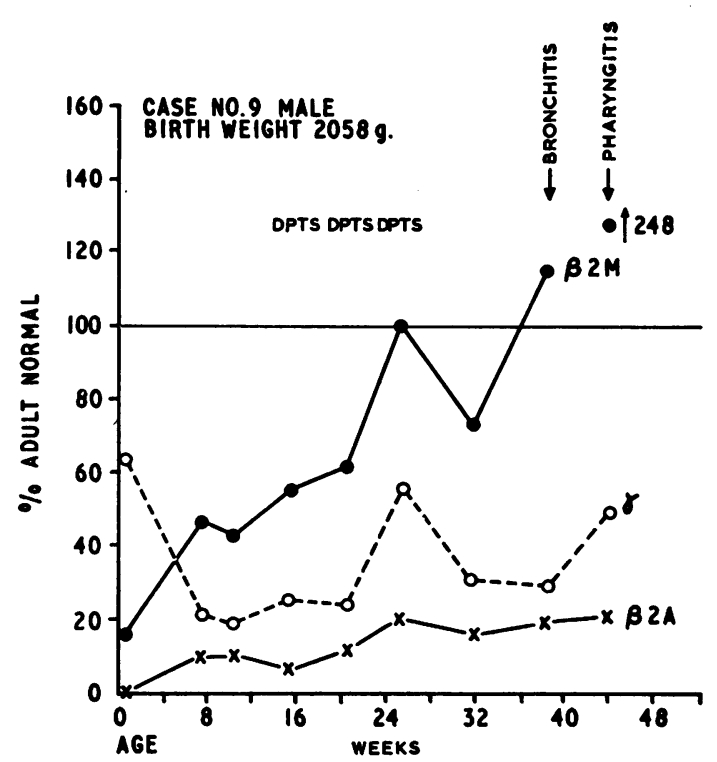

FIG. 5.-The values of the immunoglobulins in Case 9 expressed as a percentage of the concentration in pooled normal adult serum and plotted against age of the child. Episodes of infection are indicated by the arrows. Immunizing injections against diphtheria, pertussis, tetanus, and poliomyelitis (Salk) are indicated by the abbreviations DPTS at the appropriate ages.

muscular injection. Between 27 and 44 weeks he was in and out of hospital with a number of infections and a persistent respiratory infection raised the possibility of cystic fibrosis. However, the sweat chlorides were normal. Two further injections of $\gamma$-globulin were given because of the persistently low plasma $\gamma_{2}$-globulin level. It should be noted, however, that the $\beta_{2 \mathrm{M}}$-globulin rose to $100 \%$ of normal at 37 weeks. The $\gamma_{2}$-globulin finally reached normal values at about 1 year of age at which time the $\beta_{2 \mathrm{M}}$ fraction had decreased again. After the age of 1 year this infant had little infection and thrived normally.

Fig. 7 shows the immunoglobulin levels in another infant (a male, birth weight 2,041 g., gestation 32 weeks) who also had a number of infections during the early weeks and months of life but, unlike Case 2, this infant did not show hypo- $\gamma$-globulinaemia. In fact the $\gamma_{2}$-globulin level did not decrease in the usual manner from the birth level of $75 \%$ of adult normal. The $\beta_{2 \mathrm{M}}$-globulin level rose fairly rapidly to $69 \%$ at 11 weeks of age. This infant at 48 weeks showed one of the highest $\beta_{2 \mathrm{~m}}$-globulin levels we recorded $(340 \%)$ and was the only case in which the $\beta_{2 A^{-}}$ globulin reached normal concentrations $(119 \%$ at 16 months of age).

The infant represented in Fig. 8 (female, birth weight 1,219 g., 29 weeks' gestation) was a tiny baby whose $\gamma$-globulin level decreased rapidly from $148 \%$ at birth to $30 \%$ at 17 weeks. The $\beta_{2 \mathrm{M}}$-globulin level rose rapidly to $93 \%$ at 17 weeks and to $343 \%$ at 22 weeks. This infant remained completely well in spite of the hypo- $\gamma$-globulinaemia and there were no infections until 33 weeks of age.

Case 1 (a female, birth weight 1,673 g., gestation

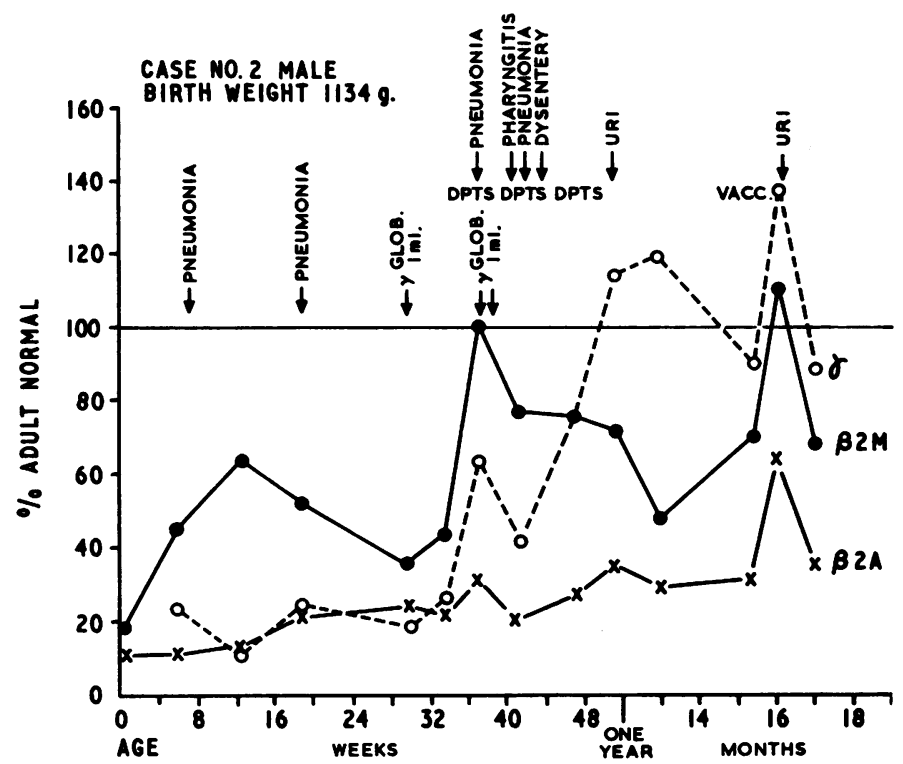

FIG. 6. - Immunoglobulins in Case 2. URI = upper respiratory infection. VACC = vaccination. Legend otherwise as in Fig. 5 . This infant also received 3 injections of commercial $\gamma$-globulin as indicated (see text). 


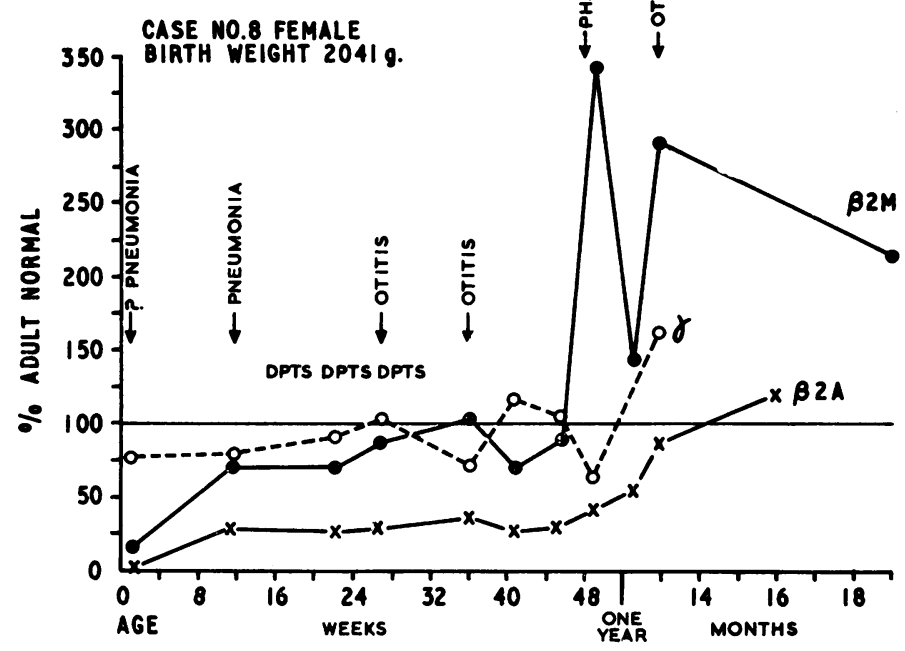

FIG. 7.-Immunoglobulins in Case 8. Legend otherwise as in Fig. 5.

34 weeks) (Fig. 9) was followed until nearly 2 years of age. The $\beta_{2 \mathrm{M}}$-globulin level rose rapidly to $240 \%$ at 28 weeks despite only one minor infection. The $\beta_{2 \mathrm{~A}}$-globulin level in this infant was still only $44 \%$ of normal the last time she was seen at $21 \frac{1}{2}$ months of age.

The number of infants studied was too small for any statistical analysis of immunoglobulin level in relation to birth weight or gestational age.

It was also not possible to show any statistically significant correlation between the number and severity of infection and the concentrations of any of the three immunoglobulins. In a number of cases a high peak of the $\beta_{2 \mathrm{M}}$-globulin occurred in association with an infection (e.g. Cases 9 and 8, Figures 5 and 7), but in an equal number of cases there was no such association (e.g. Case 7, Fig. 8). Similarly with the $\gamma_{2}$-globulin levels there was no correlation between the depth of the 'trough' and the incidence of infection.

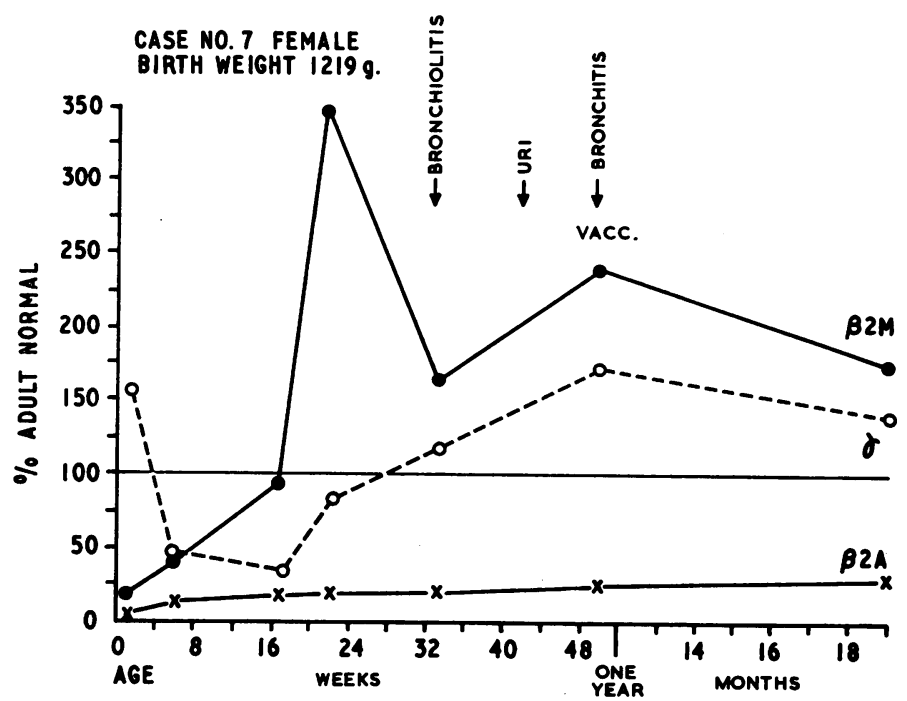

Fig. 8.-Immunoglobulins in Case 7. Legend otherwise as in Figs. 5 and 6. 


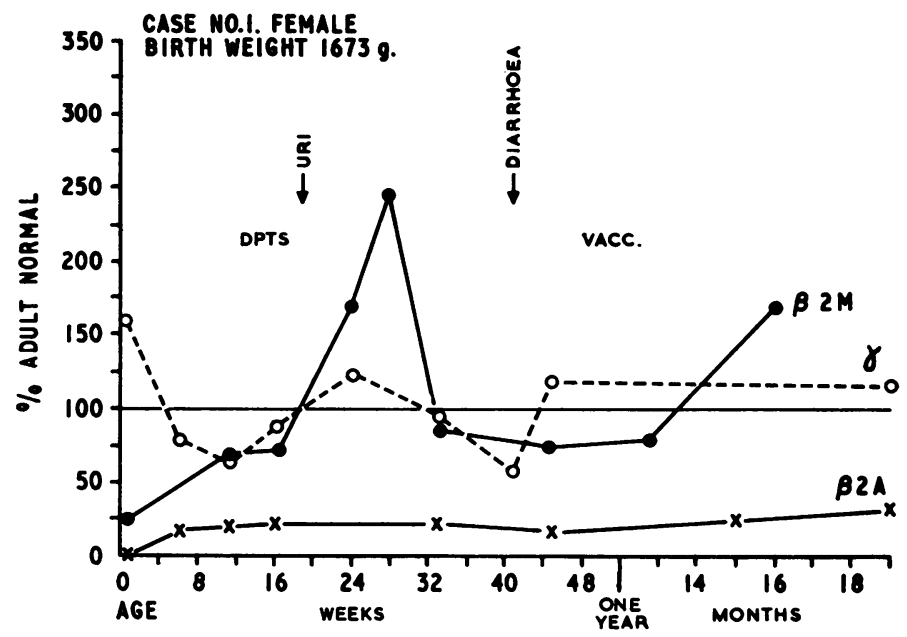

FIG. 9.-Immunoglobulins in Case 1. Legend otherwise as in Figs. 5 and 6.

We were also unable to show any change in immunoglobulin concentration following immunization against diphtheria, pertussis, tetanus, poliomyelitis, and small-pox.

\section{Discussion}

In general the results we obtained in this group of 19 premature infants are in agreement with the results in other studies of immunoglobulin concentrations in young infants (Hitzig, 1957, 1961; Scheidegger and Martin du Pan, 1957; Franklin and Kunkel, 1958; West et al., 1962). Our attempt to follow the changes of immunoglobulin concentration in a group of premature infants during the first year or so of life has, we feel, been of some value even if only to demonstrate the great variability in the values obtained. The changes in the $\beta_{2 \mathrm{M}}$.globulin concentration were of considerable interest. All infants showed some $\beta_{2 M^{-}}$-globulin in their plasma by the quantitative assay during the first few days of life, though no line of precipitation could be identified on the immunoelectrophoretogram at levels below about $40 \%$ of adult normal. Our finding of low levels of $\beta_{2 M}$ at birth, or within a few days of birth, supports the work of others that this protein can be synthesized by the foetus in utero, since $\beta_{2 \mathrm{M}}$-globulin does not cross the placenta. Synthesis after birth evidently continues at a very rapid rate because adult normal values were reached by 20 to 24 weeks of age. This rapid synthesis is occurring at a time when the $\gamma_{2}$-globulin level is decreasing because of katabolism and little or no synthesis. This supports the recent concept that the premature infant is by no means immunologically incompetent but is able to produce antibody by means of the $\beta_{2}$-macroglobulin mechanism before $\gamma_{2}$-globulin synthesis begins (Fink et al., 1962; Smith and Eitzman, 1964).

It appears that the $\beta_{2 \mathrm{~A}}$-globulin synthesis does not occur to any degree in the foetus, but synthesis evidently begins during the first few weeks after birth and increases very slowly during the first year of life. By 1 year the mean concentration in the infants was only $28 \%$ of the average normal level. These findings were similar to those of West et al. (1962).

We were not able to demonstrate a statistically significant correlation between the concentration of the immunoglobulins in the plasma of the premature infants and the incidence of infection. Such an association might have been missed for several reasons. The follow-up of a few of the infants was not always as good as we would have wished. Some cases attended rather irregularly and we were dependent upon the mother's history about minor infections that had occurred in the interval between two visits if she did not consider the baby ill enough to bring to the hospital at the time of the infection. In addition the total number of infants was too small for much statistical analysis.

Case 2 (Fig. 6) was a very immature baby who had a lot of infection during the first 11 months of life. $\mathrm{He}$ had profound and prolonged hypo- $\gamma$-globulinaemia. At 12 weeks of age the $\gamma_{2}$-globulin concentration was only $10 \%$ of the mean adult level which would correspond to $110 \mathrm{mg} . / 100 \mathrm{ml}$. In addition the $\beta_{2 \mathrm{M}}$-globulin level remained lower than the average and did not reach the adult mean until 37 weeks. This baby appears to be similar to Cases 11 and 12 of West et al. (1962) with transient hypo-y- 
globulinaemia or a 'slow starter'. Four other infants might also have been considered 'slow starters' with $\gamma_{2}$-globulin levels of less than $20 \%$ (220 mg. $/ 100 \mathrm{ml}$.) of the adult mean and in 3 of them the $\beta_{2 \mathrm{M}}$-globulin also remained low. One of these infants had no infections at all and the other two had minor infections such as skin pustules and conjunctivitis.

Clearly there is much more to be learned about immunity in the premature infant. We did not measure antibody production in this series of infants, and this will remain a fruitful field for further investigation.

Besides the immunoglobulins, a number of other protein fractions appeared to be diminished or absent on the immunoelectrophoretic slides of the plasma of these infants during the first few weeks of life. These other fractions were not analysed in the present study but it is hoped to do this at a later date.

\section{Summary}

A study was made of the immunoglobulins in a group of 19 premature infants. Blood was collected from the infants during the first few days of life and thereafter at approximately monthly intervals until 12 months of age. In a few cases it was possible to follow the infant in the second year of life.

Each plasma or serum sample was analysed qualitatively by a modification of the microimmunoelectrophoretic technique of Scheidegger (1955) and the three main immunoglobulins, $\beta_{2}$-macroglobulin $\left(\beta_{2 \mathrm{M}}\right), \beta_{2 \mathrm{~A}}$-globulin, and $7 \mathrm{~S}-\gamma$ globulin were assayed quantitatively.

The $\beta_{2 \mathrm{~A}}$-globulin was usually found to be absent at birth, confirming the observations of other workers. Thereafter the levels rose very slowly and at 1 year the mean concentration was only $28 \%$ of the average adult normal. The mean $\beta_{2 M}$ concentration at birth was $25 \%$ of the adult value and during the first few months of life rose very rapidly to reach normal adult values between 20 and 24 weeks of age. The levels of $\gamma_{2}$-globulin approximated the level found in normal adult serum at birth, presumably because of placental transfer from the mother. The levels then declined rapidly to a mean of $25 \%$ of normal between 12 and 16 weeks of age, after which a rise occurred to reach the adult average value at 12 months of age.

There was no statistically significant correlation between the incidence of infection in these 19 infants and the level of any of the three immunoglobulins.

We acknowledge the help of Drs. W. L. Parker and $H$. Taylor in many aspects of this investigation and thank both of them for reviewing the manuscript.

This work was supported by a grant from Parke, Davis and Co. Ltd. and from the Department of National Health and Welfare of Canada.

\section{REFERENCES}

Chodirker, W. B., and Tomasi, T. B., Jr. (1963). Gamma-globulins: Quantitative relationship in human serum and nonvascular fluids. Science, 142, 1080.

Fahey, J. L., and Lawrence, M. E. (1963). Quantitative determination of $6.6 \mathrm{~S} \gamma$-globulins, $\beta_{2 \mathrm{~A}^{-}}$globulins and $\gamma_{1}$-macroglobulins in human serum. J. Immunol., 91, 597.

Fink, C. W., Miller, W. E., Jr., Dorward, B., and LoSpalluto, J. (1962). The formation of macroglobulin antibodies. II. Studies on neonatal infants and older children. J. clin. Invest., 41, 1422.

Franklin, E. C. (1962). The structure, function and significance of the immune globulins. Vox Sang. (Basel), 7, 1.

- and Kunkel, H. G. (1958). Comparative levels of high molecular weight (19S) gamma globulin in maternal and umbilical cord sera. J. Lab. clin. Med., 52, 724.

Heremans, J. F., and Vaerman, J.-P. (1962). $\beta_{2 \mathrm{~A}-\mathrm{globulin}}$ as a possible carrier of allergic reaginic activity. Nature (Lond.), 193, 1091.

— - - and Vaerman, C. (1963). Studies on the immune globulins of human serum. II. A study of the distribution of anti-brucella and anti-diphtheria antibody activities among $\gamma_{88}-$, $\gamma_{1 M^{-}}$and $\gamma_{1 \Lambda^{-}-g l o b u l i n}$ fractions. J. Immunol., $91,11$.

Hitzig, W. H. (1957). Die physiologische Entwicklung der 'Immunglobuline' (Gamma- und Beta ${ }_{2}$-Globuline). Helv. paediat. Acta, $12,596$.

(1961). Das Bluteiweissbild beim gesunden Säugling : spezifische Proteinbestimmungen mit besonderer Berücksichtigung immunochemischer Methoden. ibid., 16, 46.

Hodes, S. L., Berger, R., Ainbender, E., Hevizy, M. M., Zepp, H. D. and Kochwa, S. (1964). Proof that colostrum polioantibody is different from serum antibody. American Pediatric Society, Seattle.

Knapp, E. L., and Routh, J. I. (1949). Electrophoretic studies of plasma proteins in normal children. Pediatrics, 4, 508.

LoSpalluto, J., Miller, W., Jr., Dorward, B., and Fink, C. W. (1962). The formation of macroglobulin antibodies. I. Studies on adult humans. J. clin. Invest., 41, 1415.

Oberman, J. W., Gregory, K. O., Burke, F. G., Ross, S., and Rice, E. C. (1956). Electrophoretic analysis of serum proteins in infants and children. I. Normal values from birth to adolescence. New Engl. J. Med., 255, 743.

Orlandini, T. O., Sass-Kortsak, A., and Ebbs, J. H. (1955). Serum gamma globulin levels in normal infants. Pediatrics, 16, 575.

Rockey, J. H., and Kunkel, H. G. (1962). Unusual sedimentation and sulfhydryl sensitivity of certain isohemagglutinins and skinsensitizing antibody. Proc. Soc. exp. Biol. (N.Y.), 110, 101.

Scheidegger, J.-J. (1955). Une micro-méthode de l'immunoélectrophorèse. Int. Arch. Allergy, 7, 103.

_- and Martin du Pan, R. (1957). Étude immunoélectrophorétique des protéines sériques du nouveau-né et du nourisson. Étud. néo-natal., 6, 135.

Smith, R. T., and Eitzman, D. V. (1964). The development of the immune response. Characterization of the response of the human infant and adult to immunization with salmonella vaccines. Pediatrics, 33, 163.

West, C. D., Hong, R., and Holland, N. H. (1962). Immunoglobulin levels from the newborn period to adulthood and in immunoglobulin deficiency states. J. clin. Invest., 41, 2054. 